\title{
Leituras de Émile Benveniste
}

\author{
Daiane Neumann ${ }^{1}$ \\ Programa de Pós-Graduação em Letras, Universidade Federal de Pelotas, Pelotas, RS, Brasil
}

Valdir do Nascimento Flores ${ }^{2}$

Programa de Pós-Graduação em Letras, Universidade Federal do Rio Grande do Sul, Porto Alegre, RS, Brasil

\section{Apresentação}

Não há apenas uma maneira de contar a história; não há nem mesmo uma única história para ser contada. Há histórias e há pontos de vista. Isso é até paradoxal. Nas palavras do filósofo Paul Ricoeur:

a permanente ameaça de confusão entre rememoração e imaginação [...] afeta a ambição de fidelidade na qual se resume a função veritativa da memória. E no entanto ... . E no entanto, nada temos de melhor que a memória para garantir que algo ocorreu antes de formarmos sua lembrança (RICOEUR, 2007, p. 26).

O ano é 2005. Trata-se da época da publicação de um pequeno manual que buscava fazer a apresentação de algumas teorias da enunciação e defender a existência disciplinar de uma linguística da enunciação. O título não é nada surpreendente: Introdução à linguística da enunciação (FLORES; TEIXEIRA, 2005).

Gostaríamos de assinalar essa informação como um marco importante para o ponto de vista da história que aqui assumimos. Ele marca um antes e um depois que, para nós, tem especial relevância: é o primeiro esforço público de trazer à tona a necessidade de emergência e de reconhecimento de um dado campo disciplinar no interior da linguística brasileira.

Evidentemente, ao afirmarmos isso, não desconhecemos que há no Brasil, desde muito tempo, estudos voltados à enunciação - nos quais a influência de Émile Benveniste é bastante evidente ${ }^{3}$ - em relação a diferentes áreas da linguística (discurso, texto etc.). No entanto, o que queremos chamar a atenção é que a busca de uma consolidação disciplinar é recente entre nós, e o ano de 2005, talvez, tenha valor importante nessa narrativa.

Ora, um campo disciplinar, para se instituir em uma dada configuração institucional e epistemológica, necessita ancoragem em material de grande circulação, que permita certa

\footnotetext{
1 Professora Adjunta dos cursos de Letras e do Programa de Pós-Graduação em Letras da UFPEL. Orcid: https://orcid.org/0000-0002-7363-0375. E-mail: daiane neumann@hotmail.com.

2 Professor Titular em Linguística e Língua Portuguesa do Instituto de Letras da UFRGS. Pesquisador Pq-CNPq. Orcid: https://orcid.org/0000-0003-2676-3834. E-mail: vnf.ufrgs@gmail.com.

${ }^{3}$ Ver: Brait (1995); Brait (2001); Cremonese (2009); Flores e Teixeira (2011); Flores (2016); Flores (2017).
} 
didatização - no sentido de tornar mais acessível - do saber teórico especializado. 0 Dicionário de linguística da enunciação, publicado em 2009, cumpre exatamente esse papel, na medida em que se configura em uma obra de referência que procura estabelecer uma terminologia especializada do campo enunciativo, além de definições objetivas dessa terminologia.

Felizmente, chegamos em 2020 com uma linguística da enunciação instituída. Mas há mais!

No âmbito, especificamente, da teoria de Émile Benveniste, a história recente das ideias linguística no Brasil viu muita coisa se alterar. Deixamos de ler Benveniste na dependência de quadros teóricos exteriores (análise do discurso, linguística do texto, pragmática etc.) para lê-lo em si e por si. E é o nascimento dessa perspectiva que queremos aqui assinalar. Contribuíram para isso, sem dúvida, o 1 o Colóquio Leituras de Émile Benveniste, ocorrido sob os auspícios da Pontifícia Universidade Católica do Rio Grand do Sul, em 20044, e o 2 - Colóquio Leituras de Émile Benveniste, ocorrido na Universidade de Passo Fundo, em $2018^{5}$. Por último, temos a alegria de trazer à luz este número da Revista Linguagem \& ensino que reúne, dentre outras contribuições recebidas na chamada, textos de especialistas na obra benvenistiana, apresentados por ocasião do 3 o Colóquio Leituras de Émile Benveniste, ocorrido na Universidade Federal de Pelotas, em 2019.

Desde o início dessa história que aqui nos propusemos a contar, muita coisa mudou. Deixamos de ver Benveniste apenas como o "pai da teoria da enunciação" - designação esta que, não raras vezes, contribui para minimizar a envergadura da obra do linguista -, e passamos a ver nesse linguista, nesse "antropólogo da linguagem" ${ }^{6}$, uma reflexão sobre a linguagem em geral na qual o homem tem papel e lugar determinantes.

Não seria faltar com a modéstia dizer que, hoje, o Brasil é um centro importante de referência nos estudos benvenistianos. Lemos, traduzimos, discutimos e investigamos as ideias do mestre em uma amplitude nunca antes experimentada na linguística brasileira.

E como poderia seria de outra maneira? Benveniste é um autor que transcende as meras fronteiras disciplinares. Seus "problemas" de investigação são problematizações da linguagem em seu conjunto. Elas convocam o linguista a dialogar com a linguística em suas diferentes vertentes, sem dúvida, mas também com as diversas áreas do conhecimento, o que é, no mínimo, fundamental para que a linguística - ciosa de um tecnicismo imanentista - não se confine a um isolamento disciplinar. É Benveniste mesmo quem, já em 1963, formula a preocupação:

Durante estes últimos anos, sobrevieram, nos estudos que se fazem sobre a linguagem e as línguas, mudanças consideráveis cujo alcance ultrapassa mesmo o horizonte, no entanto vasto, da linguística. Essas mudanças não se compreendem à primeira vista; esquivam-se na sua própria manifestação; com o tempo tornaram muito mais penoso o acesso aos trabalhos originais, que se encrespam de uma

\footnotetext{
${ }^{4}$ Ver: Revista Letras de Hoje, v. 39, n. 4, 2004.

${ }^{5}$ Ver: Revista Desenredo, v. 14, n. 3, 2018.

${ }^{6}$ Cf. Coquet e Fenoglio (2014).
} 
terminologia cada vez mais técnica. É inegável: encontra-se grande dificuldade para ler os estudos dos linguistas, mas ainda mais para compreender as suas preocupações. A que visam e que fazem com esse algo que é o patrimônio de todos os homens e não cessa de atrair a sua curiosidade: a língua? Tem-se a impressão de que, para os linguistas de hoje, os fatos da linguagem se transmudam em abstrações, se tornam nos materiais inumanos de construções algébricas ou servem de argumentos a discussões áridas sobre método, e de que a linguística se afasta das realidades da linguagem, e se isola das outras ciências humanas (BENVENISTE, 1988, p. 20).

A essa preocupação, o mestre responde com uma esperança no fazer do linguista cuja efetiva concretização caberia ser avaliada nos dias de hoje:

Ora, é exatamente o contrário. Comprova-se, ao mesmo tempo, que esses métodos novos da linguística assumem o valor de exemplo e mesmo de modelo para outras disciplinas, que os problemas da linguagem interessam agora a especialidades muito diversas e cada vez mais numerosas e que uma corrente de pesquisa leva as ciências do homem a trabalhar dentro do mesmo espírito que anima os linguistas (BENVENISTE, 1988, p. 19-20).

Como podemos ver, há certo otimismo na avaliação de Benveniste. Acreditamos, porém, que, na atualidade, cabe advertir: "a crescente especialização da linguística pode obscurecer o fato de que a linguagem, como propriedade humana que é, não se conforma integralmente a nenhuma disciplina" (FLORES, 2019, p. 35). Por isso, cabe a recomendação, explicitamente benvenistiana: "o linguista, sem ter de abrir mão do rigor que caracteriza o seu fazer, pode ficar mais atento aos evidentes sinais de que a linguística sofre de uma quase total ausência de laço social" (FLORES, 2019, p. 35-36).

Tendo em vista esse cenário, é com certo regozijo que trazemos a público este número da Revista Linguagem \& ensino que, como dissemos antes, reúne, em forma de artigos, dentre outras contribuições, também as comunicações que integraram o 3o Colóquio sobre Benveniste. O leitor verá que o tempo passou, que as discussões se alteraram significativamente, que os diálogos se ampliaram e que, principalmente, Benveniste permanece uma fonte inesgotável de reflexão.

Os artigos que ora convidamos à leitura, na tentativa de abarcar essa amplitude do pensamento do linguista, inserem-se em quatro eixos de reflexão, conforme proposta da chamada para este dossiê, quais sejam: 1) Efeitos da teoria da linguagem de Benveniste na proposição de outras teorias da linguagem; 2) Efeitos da teoria de Benveniste na composição da reflexão de campos conexos aos estudos da linguagem; 3) Interpretações da teoria da linguagem de Benveniste que possibilitam a formulação de prospecção teórica; 4) Interpretações da teoria da linguagem de Benveniste a partir de estudos intra-teóricos.

É certo que testemunhamos grandes mudanças acerca da presença de Benveniste entre nós. Contribuíram para isso todos os autores que estão presentes neste volume (e nos anteriores), certamente, mas também todos os que não estão - e são muitos - ou porque já não se encontram mais entre nós (a inesquecível Marlene Teixeira, leitora maior de Benveniste), ou porque apenas participaram via debate ou porque contingências impediram 
sua contribuição neste momento. Devemos nos esforçar para, cada vez mais, aumentar a participação e a presença de todos.

O Colóquio já é uma instituição para nós. Ele deverá continuar a acontecer porque precisamos dele para continuar a transformar as "palavras aladas" de Homero em objeto de estudo. Enfim, ele continuará - estamos certos disso - porque é urgente que se mantenha viva a palavra de um linguista que acredita que "tudo o que diz respeito à linguagem é objeto da linguística" (BENVENISTE, 1989, p. 29).

Boa leitura!

\section{Referências}

BENVENISTE, Émile. Problemas de linguística geral I. Tradução de Maria da Glória Novak e Maria Luisa Neri. Campinas: Editora da UNICAMP, 1988.

BENVENISTE, Émile. Problemas de linguística geral II. Tradução de Eduardo Guimarães et al. Campinas: Editora da UNICAMP, 1989.

BRAIT, Beth. La reception d'Émile Benveniste au Brésil: quelques aspects. Revista Língua e Literatura, v. 21 , n. 1, p. 197-215, 1995. https://doi.org/10.11606/issn.25945963. lilit.1995.114558

BRAIT, Beth. (Org.). Estudos enunciativos no Brasil: história e perspectivas. Campinas: Editora da UNICAMP, 2001.

COQUET, Jean-Claude; FENOGLIO, Irène. Introdução. In: BENVENISTE, Émile. Últimas aulas no Collège de France 1968 e 1969. Tradução de Daniel Costa da Silva et al. São Paulo: Editora Unesp, 2014. p. 197-198.

CREMONESE, Lia. A linguística da enunciação no Brasil. In: Anais do SILEL, v. 1. Uberlândia: EDUFU, 2009. p. 1-11.

FLORES, Valdir do Nascimento et al. Dicionário de linguística da enunciação. São Paulo: Editora Contexto, 2009.

FLORES, Valdir do Nascimento; TEIXEIRA, Marlene. Introdução à linguística da enunciação. São Paulo: Editora Contexto, 2005.

FLORES, Valdir do Nascimento. As teorias enunciativas e a linguística no Brasil: o lugar de Émile Benveniste. Antares: Letras e Humanidades, v. 8, n. 15, p. 2-14, 2016.

FLORES, Valdir do Nascimento. Problemas gerais de linguística. Petrópolis: Vozes, 2019.

RICOEUR, Paul. A memória, a história, o esquecimento. Tradução de Alain François et al. Campinas : Editora da Unicamps, 2007.

TEIXEIRA, Marlene; FLORES, Valdir do Nascimento. Linguística da enunciação: uma entrevista. Revista Virtual de Estudos da Linguagem, v. 9, n. 16, p. 406-425, 2011. 